\title{
NDD.06. Effects of a sulfated agaran from red seaweed Gracilaria cornea in 6-OHDA hemi-parkinsonian rats
}

\author{
SOUZA, R.BA ${ }^{A}$ FROTA, .A.F', SOUZA, R.S ${ }^{C}$, AGUIAR, L.M.V. ${ }^{B}$, BENEVIDES, N.M.B. ${ }^{A}$.
}

aBiochemistry and Molecular Biology Department of the Federal University of Ceará, Fortaleza - Ce - Brazil

bMedicine Faculty of the Federal University of Ceará, Sobral - Ce - Brazil; 'Biological Sciences Center of the State University of Acaraú Valley, Sobral - Ce - Brazil.

Introduction: Animal models of PD induced by the neurotoxin 6-hydroxydopamine (6OHDA) show locomotion and behavioral alterations mostly caused by the oxidative and inflammatory process induced by this neurotoxin. Sulfated agaran is a polysaccharide with sulfate groups found in the red seaweed Gracilaria cornea (SA). Recently, a study with SA showed anti-inflammatory effects and absence of toxic effects in vivo. The aim of this work was to evaluate the neuroprotective effects of SA after behavioral and locomotion alterations-induced by 6-OHDA intrastriatal injection in rats and to evaluate the safety of the intraestriatal administration of this polysaccharide in vivo. Methods: The seaweed was collected from Flecheiras beach, Brazil. SA was obtained as previously described by Coura et al (2012). Male Wistar rats (220-300 g) were randomically divided in eight groups $(n=10$ animals per group). Rats were anesthetized and treated with AS $(15,30$ or $60 \mu \mathrm{g})$ alone or after 6-OHDA $(20 \mu \mathrm{g})$ injection; 6-OHDA $(20 \mu \mathrm{g})$ alone; or saline (sham group). All treatments were realized through stereotaxic injection into the right striatum and solutions were prepared diluted in saline $(0.9 \%$; with $0.01 \%$ ascorbic acid). Animals were maintained under ad libitum feeding conditions. This study was approved by the Ethics Committee for Animal Research of the Federal University of Ceará - CEPA (no 45/13). The rats weight were measured daily for ponderal curve analysis. On the $14^{\text {th }}$ day, rats were subjected to behavioral evaluation by the open-field test and the rotational test after apomorphine (3 $\mathrm{mg} / \mathrm{Kg})$. Results: The open-field test showed an increase $(\mathrm{p}<0.01)$ in the locomotor activity of the $6-\mathrm{OHDA}+\mathrm{SA}(30$ and $60 \mu \mathrm{g}$ ) groups in $63.1 \pm 5.7$ and $74.9 \pm 5.8$ (numbers lines crossing), respectively, in relation to 6-OHDA group (47.4 \pm 3.7$)$. 6-OHDA+SA $(15,30$ or 60 $\mu \mathrm{g})$ groups had the rotation number reduced $(\mathrm{p}<0.001)$ in 80,83 and $91 \%$, respectively, in comparison to 6-OHDA group. Additionally, rats submitted to intraestriatal SA injection (15, 30 or $60 \mu \mathrm{g}$ ) alone did not show statistical differences compared to the sham group in the overall tests utilized. Conclusions: SA from seaweed G. cornea show neuroprotective effects against locomotion disturbances induced by 6-OHDA injection into the striatum. SA did not show behavioral and ponderal changes in comparison to the sham group, suggesting safety.

Keywords: Agaran sulfated, 6-hydroxydopamine, Safety

\section{Funding: FUNCAP, CAPES.}

SOUZA, R.B.; FROTA, .A.F.; SOUZA, R.S.; AGUIAR, L.M.V.; BENEVIDES, N.M.B. 2013. Effects of a sulfated agaran from red seaweed Gracilaria cornea in 6-OHDA hemi-parkinsonian rats, p.35. In: Oriá, Reinaldo Barreto; Andrade, Geanne Matos de; Bruin, Veralice Meireles S. de. I International Symposium in Neuroscience Meeting [Blucher Neuroscience Proceedings n.1 v.1]. São Paulo: Blucher, 2014, http://dx.doi.org/10.5151/isnm-sine30 